\title{
Investments in Fire Management: Does Saving Lives Cost Lives?
}

\author{
Brian Ashe, Felipe Dimer de Oliveira and John McAneney ${ }^{1}$
}

\section{Abstract}

The total cost of structural fires and bushfires in Australia was estimated at around A $\$ 18$ billion in 2010, or about 1.5 per cent of GDP. This cost includes some A\$16 billion devoted to managing the risk. At the same time, Australia's fire fatality rate of 0.6 per 100000 of population, already low by international standards, has proved resistant to increasing expenditure on fire management and protection. Following a concern that this expenditure might encompass an overinvestment compared with the real risk, this paper examines the regulatory cost of this investment. Since on average poorer people have worse health outcomes, and governments or companies have no alternative but to pass on increased costs or taxes, it is possible to estimate the lives forgone, on account of an increased mortality rate, of any overinvestment. Adapting a model of Keeney (1997) for Australian conditions, we determine the Australian willingness to spend (WTS) for preventing a loss of a life in the fire space to be between $A \$ 20$ and $A \$ 50$ million, depending upon how these costs or taxes are imposed upon the population. If we accept, by way of example, the results of an expert elicitation (Ashe and McAneney 2011) to imply an overinvestment in fire prevention and management of the order of A\$4.5 billion per annum (2010 dollars), this excess would imply between 90 and 225 extra fatalities annually. These numbers are of the same order as the annual average number of fire fatalities actually experienced. The analysis shows the importance of carefully evaluating the unintended costs of any new safety regulations and particularly in insuring that the costs are at least grosso modo in line with the purported benefits.

\section{Background}

This paper attempts to evaluate the opportunity cost of investments in managing fire in Australia. While much debate takes place about fire, particularly in respect of bushfire (wildfire), very little of this is informed by a true understanding of its cost. Previous work by Ashe, McAneney and Pitman (2009) has helped

1 Risk Frontiers, Macquarie University. Principal contact, Brian Ashe, bswashe@gmail.com 
quantify the aggregate cost of investments in fire mitigation, response capability and the consequences of fire, a cost which they put at about A $\$ 12000$ million or 1.3 per cent of GDP in 2005.

Ashe, McAneney and Pitman (2009) also showed that of the total cost of fire, nearly 86 per cent was accounted for by investments in fire safety and mitigation (termed costs in anticipation) and maintaining fire services (costs in response) and only about 14 per cent could be attributed to the costs of dealing with the consequences of fire. A priori we might expect that if investments in anticipation and response were reduced, then the consequences of fire should increase; but, if so, by how much? An updated breakdown of the cost categories of Ashe, McAneney and Pitman (2009) is given in Table 1 and shows that by 2010, the total cost of fire had increased to A $\$ 18000$ million, or 1.5 per cent of GDP, whereas the proportion of the cost of dealing with the consequences of fire had dropped to 9 per cent. While this reduction in consequences in terms of fire damage is gratifying, does the increase in investment in dealing with fire represent good value for money? These are important questions which this study attempts to explore for the first time.

International experience reviewed by Ashe, McAneney and Pitman (2011) suggests that the economic efficiency in fire-management investments cannot be simply assumed. This study employed structured expert judgement to explore whether Australian fire professionals perceived the current allocation of investment in mitigation and response to be optimal. Of the 26 respondents, none believed an increase in investment in anticipation or response would be cost effective. Even more relevant to the current study was the fact that most respondents were of the view that net economic benefits would accrue from decreases in investment, even though this might come at the expense of an increase in property damage and loss of life.

Actual decisions about investments in fire prevention and management are intrinsically political, with the ultimate driver of political outcomes being public opinion. If the system of investments for dealing with the fire risk were sub-optimal, then it is likely, at least in part, that this arises from the community's perception (or misperception) of the risk. With this in mind, Ashe and McAneney (2011) surveyed public opinion and found that, on average, Australians significantly overestimated the impact of fire in respect of firerelated deaths. Their follow-up survey undertaken in April 2009, following the 7 February 2009 Victorian bushfires and a death toll of 173 and heavy media coverage, showed this concern to be further exaggerated (ibid.). This result is in accord with other studies showing the strong influence of the media on public perceptions of risk (for example, Flynn, Slovic and Kunreuther 2001) and is yet another manifestation of the fact that when human lives are at risk, decisionmaking is rarely rational (Viscusi 1993; Tengs et al. 1995). 
Table 1: Total Cost of Fire in Australia (2010): Summary of cost components

\begin{tabular}{|c|c|c|}
\hline Cost component & $\begin{array}{l}\text { Total cost } \\
\text { (\$ million) }\end{array}$ & $\%$ of total \\
\hline Fire safety in buildings & 2835 & \\
\hline Fire-safety measures in structures / infrastructure & 4023 & \\
\hline Fire-safety education and training & 46 & \\
\hline Insurance administration & 375 & \\
\hline Fire safety in consumer items & 1849 & \\
\hline Fire research & 23 & \\
\hline Maintenance of fire-safety equipment and measures & 2743 & \\
\hline Sub-total: Cost in anticipation & 11895 & 66 \\
\hline Cost of injury due to fire & 427 & \\
\hline Property losses & 937 & \\
\hline Loss of business & 58 & \\
\hline Environmental costs & 225 & \\
\hline Heritage and cultural costs & 58 & \\
\hline Wider economic distortions & - & \\
\hline Sub-total: Cost as a consequence & 1705 & 9 \\
\hline Fire-service response costs & 2015 & \\
\hline Volunteer fire service & 2311 & \\
\hline Private fire brigade responses & 116 & \\
\hline \multicolumn{3}{|l|}{ Criminal justice costs } \\
\hline Sub-total: Cost in response & 4441 & 25 \\
\hline Total cost of fire in Australia 2010 & 18041 & 100 \\
\hline
\end{tabular}

Source: Updated from Ashe, McAneney and Pitman 2009.

\section{'Death' by regulation}

Over the past 25 years, the number of government regulations aimed at improving safety in both Europe and America has soared (Economist 2004). John Graham, appointed as America's top regulator at the Office of Management and Budget in 2001, was previously an academic who promoted the use of costbenefit methodologies to analyse risks. He called the inefficiencies of regulation 'statistical murder', arguing that bad regulation absorbs money that could be better spent to save lives another way (ibid).

Wildavsky $(1980 ; 1988)$ was the first to draw attention to the negative impacts on public health on the opportunity costs of government public-health programs. He argued that economic growth, not government regulation, has been the 
primary means by which life expectancy and health status have improved, and that government policies formulated without taking into account the scarcity of resources may often do more harm than good.

An estimation of the net number of lives saved by regulation is often referred to as a risk-risk analysis (Viscusi 1994a; 1994b). Risk-risk analysis can be a useful tool for eliminating clearly undesirable policy options in cases where the use of the cost-benefit analysis is controversial or problematic (Viscusi 1994b).

Amongst others, Kitagawa and Hauser (1973), Wildavsky (1980; 1988), Frerichs et al. (1992), Lutter and Morrall (1994), Viscusi (1993; 1994a; 1994b) and Gerdtham and Johannesson (2002) all provide support for the conclusion that the mortality rate for individuals with higher incomes is lower than that for individuals with lower incomes. Reasons for this relate, inter alia, to better nutrition, better sanitation, better healthcare, better education and better socioeconomic status - all of which are easier to come by with money.

The 'richer is safer' argument is, in its simplest form, that the costs of regulation are necessarily borne by individuals. Intermediaries such as the government or companies have no option other than to pass costs to individuals. Thus, at least temporarily, increased taxation or costs leave individuals and families poorer in the sense that they have less disposable income for other purposes, including better healthcare. And, as will be discussed below, there is good evidence that poorer people on average have worse health outcomes. Thus, at least in a statistical sense, increased regulatory costs induce fatalities.

Lutter and Morrall (1994) used the notion of a utility maximising individual to derive a general relationship between the critical income loss necessary to induce one fatality. They refer to this as society's willingness to spend (WTS) to reduce health-and-safety risks and determined its value for a number of countries. In the case of Australia, they estimated the WTS as US\$4.2 million in 1980 dollars. Adjusting this figure for changes in Gross Domestic Product (GDP), the current Australian WTS would be around about A\$15 million in 2010 dollars.

Keeney (1990) attempted to quantify this opportunity cost further in terms of statistical or regulatory fatalities. He did this by drawing upon the evidence given above that poorer people have poorer health outcomes, and combining this with the notion that government intervention reduces people's purchasing power and a statistical relationship between mortality and income. In this way, Keeney found that the cost of direct intervention - regulation — in the economy may induce more fatalities than had been previously recognised. Specifically, Keeney found that in 1980 dollars, one fatality might be induced for each 
US\$3-7.5 million cost of regulation. A priori, the introduction of new regulations or policies should not induce more statistical fatalities than the numbers of actual lives claimed to be saved by the intervention.

In the most recent work in this field, Gerdtham and Johannesson (2002) also concluded that life-saving regulations/interventions may be counterproductive if they have an indirect mortality effect through the reduction in disposable income. The income loss that will induce one 'statistical' or 'regulatory' fatality in Sweden was estimated to be US\$6.8 million when costs were borne equally among all adults.

This paper seeks to estimate society's WTS for fire risk in Australia. To our knowledge, no similar work has been undertaken in this country. The paper begins by adapting Keeney's model to Australian conditions and the investments in fire management, prevention and response. This is followed by brief consideration of a thought experiment: what would be the likely consequences for fire fatalities in Australia if an extreme laissez-faire strategy was adopted? The paper concludes with some discussion on the implications for the level of government investment in fire management and prevention and its possible utility to other areas of government intervention.

\section{Theory and methods}

The broad conceptual underpinnings of Keeney's (1990; 1994) model have been introduced above. In more recent work, Keeney (1997) refined his model to consider how the cost of regulation might vary depending upon how the financial burden was distributed amongst the population of different incomes. In other words, outcomes also depend upon how both income and the regulatory burden are distributed.

Figure 1 shows the distribution of annual family income for Australia in 200910 obtained from the Australian Bureau of Statistics (ABS). The total number of samples is five million, which is used to derive the proportions shown in Figure 1. We employ the Gross Family Income data from the 2006 census data, which provides the numbers of families with income in given income brackets and from which the fraction of the population with access to given income can be derived. We assume that the distribution of family sizes is independent of income, a conservative approach if larger families were to be wealthier than individuals who are single. For comparison, we show US data on income. ${ }^{2}$

2 From the 2012 US statistical abstract 696, 'Money Income of Families - Percent Distribution by Income Level, in Constant (2009) Dollars', at: http://www.census.gov/compendia/statab/2012/tables/12s0696.xls 


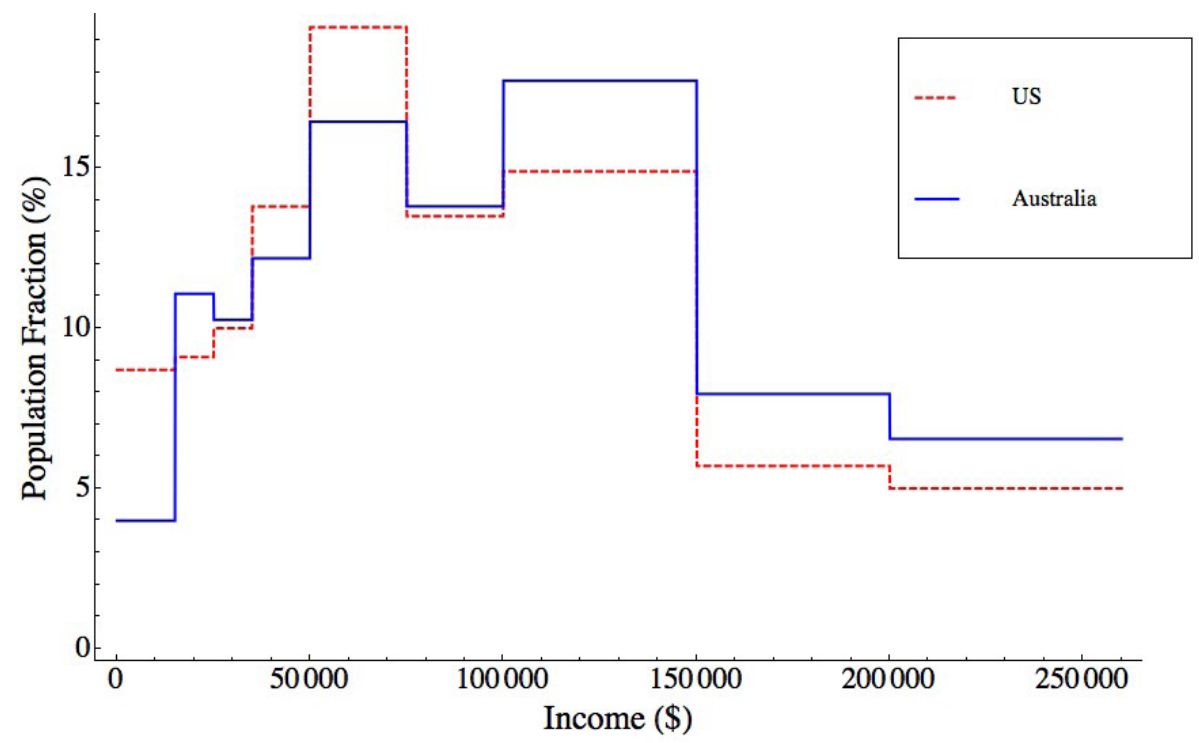

Figure 1: Fraction of the Australian and US population vs. mean annual income for 2009-2010. (The exchange rate during this time was close to parity (US\$1 $\approx A \$ 1)$ )

Source: Australian Bureau of Statistics.

Figure 1 shows broad similarities between these two countries in terms of income distribution, with the majority of both populations being middle class with modest differences in the lowest and upper income brackets. We will use this similarity, as well as those in culture and wealth, to justify using US incomemortality models in Australia.

Based on the work of Kitagawa and Hauser (1973) and Frerichs et al. (1984), Keeney (1997) employed an exponential decay model to describe the mortality rate:

$$
r(x)=a \exp (-b x)+d
$$

where $r(x)$ is the mortality rate for individuals with income $x . a, b$ and $d$ are the model parameters, with $b$ determining the rate of decay of mortality with rising income, and $a$ and $d$ constrained by the average mortality rate:

$$
\text { mean } r=(a+d) / 2
$$

The model is causal in the sense that income (or lack thereof) directly influences the mortality rate and it does not consider that healthier behaviour may be the cause of higher (or lower) income. In other words, mortality is expressed as a function of income. 
No quantitative studies of mortality rates as a function of income are available for Australia and thus our approach has been to rescale US data presented by Keeney (1997) using Purchasing Power Parity (PPP) to convert to Australian currency in 1991 and then to adjust for inflation to bring values up to 2010 . The data for this exercise came from the International Monetary Fund (www. imf.org). The PPP factor for Australian dollars in 1991 is given as $\mathrm{A} \$ 1.35$ per international dollar and the 1991-2010 Australian inflation factor is given as 1.67, resulting in a scaling factor of 2.25. (The analogous figure is 2.5 if US inflation is adjusted for first and then the result converted to 2010 Australian dollars using PPP.) In other words, a reduction in income of $\mathrm{A} \$ 2.25$ today will induce (in a statistical sense) the same increase in mortality rate as did US\$1 in 1991. This being the case, the income above which 1991 mortality rates become independent of income, around US\$70 000, maps to A \$160 000 in today's values $(2.25 \times 70,0000)$. This provides us with a re-scaled $b$-value parameter for Keeney (1997) model (equation 1) and the corresponding shape or decay rate for $r(x)$ under Australian conditions.

The remaining parameters $a$ and $d$ are determined from the national mortality rates (that is, independent of income) according to equation (2). Data from the Statistical Abstract of the United States (1990) gives a mortality rate of nine per 1000, and the Australian 2006 census (www.abs.gov.au) gives an equivalent figure of seven per 1000. We rescale the US $a$ and $d$ parameters of Keeney (1997) by a factor of $7 / 9$ to obtain the parameters for the mortality rate model, as summarised in Table 2.

Table 2: Adjusting parameter values for equation (1) for Australian conditions

\begin{tabular}{|l|l|l|l|l|}
\hline Parameter & Original US Value & $\begin{array}{l}\text { Adjustment } \\
\text { Factor }\end{array}$ & $\begin{array}{l}\text { Re-Scaled Value } \\
\text { for Australia }\end{array}$ & Explanation \\
\hline$a$ & 0.00926 & 0.8 & 0.00744 & $\begin{array}{l}\text { National Mortality } \\
\text { Rates }\end{array}$ \\
\hline$b$ & 0.0450 (per \$1000) & $1 / 2.25$ & 0.02 & $\begin{array}{l}\text { Purchasing Parity } \\
\text { Power and Australian } \\
\text { Inflation }\end{array}$ \\
\hline$d$ & 0.00422 & 0.8 & 0.0034 & Mortality Rate \\
\hline
\end{tabular}

Source: Author, from various sources.

Figure 2 illustrates Keeney's (1990) mortality rate function and the resulting Australian equivalent that follows from our assumptions as described above. 


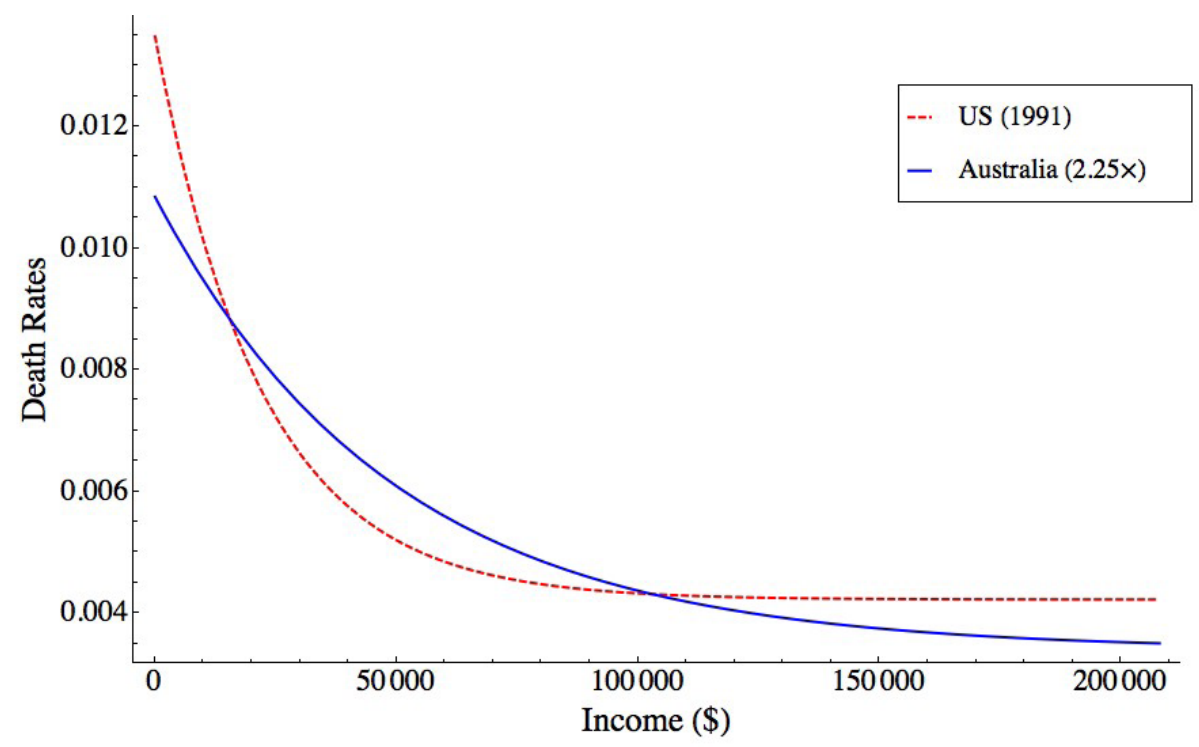

Figure 2: Mortality versus income functions for the United States (1991) and Australia (2010). Units of income are curve dependent: 1991 US\$ for the dashed line and $2010 \mathrm{~A} \$$ for the solid line

Source: Author, from various sources.

Lastly, we must consider how the burden of the cost falls across families according to income. This distribution is calculated for two scenarios: first, if costs per family $(C(x))$ were imposed uniformly across all incomes $(x)$ and therefore were independent of income, that is:

$$
C(x) \propto k
$$

and secondly, if costs were distributed proportionally amongst families, the corresponding function has the form

$$
C(x)=k x
$$

and where $k$ is a constant. According to the Keeney (1991) model, we are now in a position to estimate the number of individuals killed by regulatory costs that have an overall cost of $C_{T}$. Before doing so, we need to determine the value of the constant $k$. This can be derived since we know $C_{T}$ is the sum of all individual contributions across the Australian population or, more succinctly (for the proportional distribution of costs),

$$
C_{T}=\sum_{i}\left(N p_{i}\right) k x_{i}
$$


where $p_{i}$ is the proportion of individuals with median income $x i$ and $N$ is the total Australian population (assumed 21 million). Solving for $k$ we have

$$
k=\frac{C_{T}}{N \sum_{i} p_{i} x_{i}}
$$

Having calculated the distribution in costs, we can move forward and calculate the variation of mortality rate, $\Delta r$, due to the loss in income $(x-c(x))$ arising from the introduction of the regulation, which is given by

$$
\Delta r(x)=r(x-C(x))-r(x)
$$

The total number of statistical deaths induced by the regulation is then calculated by applying this equation to each one of the income brackets given earlier:

$$
\Delta F=\sum_{i} \Delta r\left(x_{i}\right) N p_{i}
$$

\section{Results and discussion}

\section{Willingness to spend - cost of a regulatory fatality}

The manner in which regulatory costs are allocated among individuals depends on the complex workings of the economy and the intermediaries and thus may be borne very differentially (Lutter and Morrall 1994). Here, two possibilities are separately considered: first, where all costs are shared equally among individuals regardless of income; and secondly, where costs are imposed proportional to the individual's income. Since no studies have been undertaken to determine which premise is most appropriate for Australia, the following discussion considers both. When regulatory costs are shared proportional to income, we find that the WTS is A $\$ 50$ million, and when costs are shared equally among the whole of the Australian population, the WTS reduces to A $\$ 20$ million.

By way of comparison, Lutter and Morrall (1994) estimated a corresponding figure of US $\$ 4.2$ million in 1980 dollars, which equates to approximately A $\$ 15$ million in 2010 terms. While broad agreement with the lower value from the Keeney (1997) model is comforting, given the uncertainties in its calculation, in what follows we shall employ the WTS range of A\$20-50 million.

\section{Cost of over-regulation in the fire sector}

Limited research has been undertaken into the investment in fire safety in Australia, or for that matter for any other country at a national level. 
Most studies have focused solely on the benefits of increasing fire safety (Marryatt 1988; Ramachandran 1988) without evaluating the opportunity cost of such actions. In order to advance our analysis, we need to put a figure on the extent of overinvestment in fire protection, management and response in Australia. In the absence of other information, we employ the results of the structured expert-judgement exercise of Australian fire professionals undertaken by Ashe and McAneney (2011). For the benefit of the reader, we briefly review the central findings of that exercise.

\section{Structured expert judgement}

None of the 26 respondents surveyed expected an increase in investment to result in a net economic 'gain', and all but four suggested that if the investment in anticipation were to decrease by $\mathrm{A} \$ 4000$ million, costs as a consequence would likely increase by $\mathrm{A} \$ 2000$ million. The latter scenario implies a positive net benefit in a strict economic sense of A $\$ 2000$ million. Figure 3 illustrates the modal responses from the structured expert-judgment exercise.

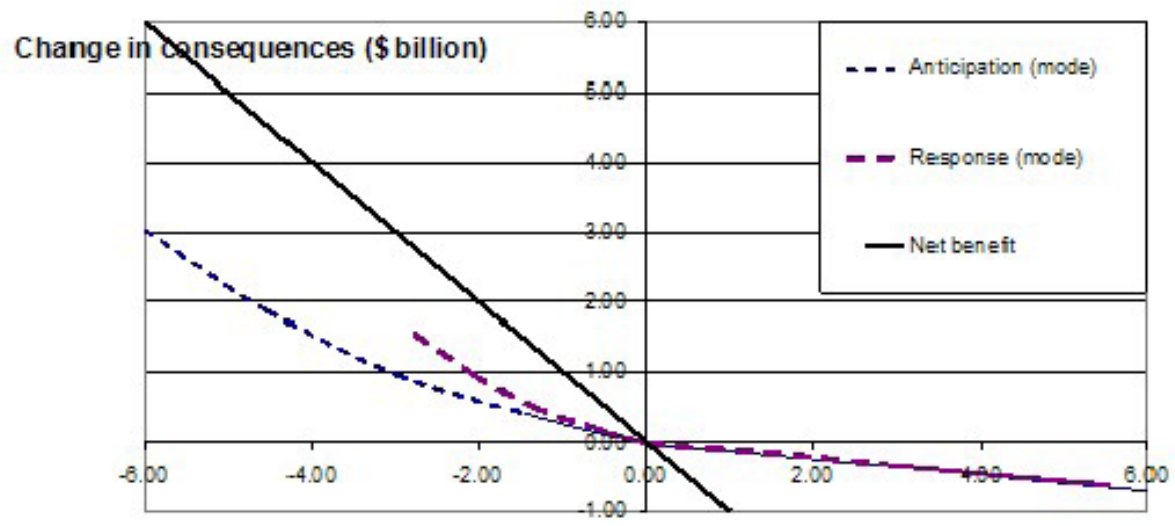

Change in investment (anticipation and response) (\$ billion)

Figure 3: Modal opinions provided by participating experts from Ashe and McAneney (2011)

Source: Ashe and McAneney, 2011.

Figure 3 implies that a net loss to the system will result from an increase in investment and a net benefit if investment were decreased. Assuming the respondents, all Australian fire professionals, have correctly understood the questionnaire (and we have no reason for thinking this was not the case), then the implications are significant. Consider the following example: given a 
total cost of the current system in 2005 of $\mathrm{A} \$ 12000$ million, if investment in anticipation were to increase by $\mathrm{A} \$ 4000$ million, consequences are anticipated to decrease by only $\mathrm{A} \$ 500$ million. This implies a negative net benefit of $\mathrm{A} \$ 3500$ million. On the other hand, if the investment in anticipation were to decrease by $\mathrm{A} \$ 5000$ million, consequences are anticipated to increase by $\mathrm{A} \$ 2000$ million, decreasing the total cost to approximately $\mathrm{A} \$ 9000$ million to give a positive net benefit of A $\$ 3000$ million. Of course, the latter comes with increased (negative) consequences, including increased loss of life and property damage, but from a strictly economic perspective, the perceived net dollar result is positive.

In what follows, we shall assume by way of example that the overinvestment is in the order of 25 per cent of the total cost of fire or $\mathrm{A} \$ 4500$ million in 2010 dollars. Dividing A $\$ 4500$ million by our estimated cost of a regulatory or statistical fatality, implies a cost of between 90 to 225 fatalities per annum, depending on whether or not the regulatory impost is imposed uniformly across the income spectrum or is based on family income. In either case, the numbers of regulatory deaths is of the same order as the annual average fatality rate of 114 - 100 lives lost in structural fires (Productivity Commission 2011) plus 14 in bushfires (Crompton et al. 2010) - under the current system of funding.

\section{Implications}

The above analysis suggests, and within the uncertainty of the estimates, the costs of regulation are of the same order as the actual fatalities. However, this is not necessarily a problem if many more lives are saved by virtue of regulatory involvement. To put some rough bounds on this number, we now explore a thought experiment that asks: 'What would happen if there was minimal investment in fire protection and management?' We approach this question only in terms of lives lost, as we know of no way to estimate the financial cost of minimal intervention in the fire system. Environmental and ecological considerations are ignored.

The fire fatality rate of 0.6 per 100000 population ( 114 per annum) in Australia is very low by international standards, and has proved very resistant to increasing expenditure on fire management and protection (Ashe, McAneney and Pitman 2009). The World Health Organisation (WHO 2002) estimated the number of deaths and mortality rates due to fire-related burns by WHO region and income group: the lowest was 0.8 for high-income groups and the highest was 11.6. The latter figure is some 20 times higher than the current Australian rate, and may provide an upper bound to possible fatality rate with only limited intervention. In Australia, this rate would correspond to approximately 2200 fire fatalities per annum. This figure must be reduced by the absence of statistical fatalities induced by regulation. We do this now. 
Based upon our estimate of the WTS per prevented fatality of A\$20-50 million of investment, we would calculate that the current total investment costs of fire in terms of anticipation and response ( $\sim \mathrm{A} \$ 16$ billion for 2010 (Ashe, McAneney and Pitman 2009)) as equivalent to 320-800 regulatory fatalities. Therefore, net fatalities in the absence of any government intervention might potentially increase from about 114 to between 1400 and 1880 ((2200 - 320) and (2200 $800)$ respectively). We contend that this outcome would be unacceptable for most Australians, even though both figures are of the same order as the current annual road toll of 1600 fatalities (BITRE 2011). Although it is not possible to propose an optimal figure for investment we posit that it lies somewhere between the current system of investment and this hypothetical minimum.

Not considered in the above analysis in respect of bushfire is that a minimalinterventionist approach would put more responsibility back on homeowners and local councils. Currently, poor land-use planning allows construction within or very close to fire-prone bushland, a practice responsible for episodic large loss of life and property destruction in extreme bushfires (Chen and McAneney 2010; Crompton et al. 2010; and Crompton 2011). However when normalised for changes in population, the average annual death toll from bushfires is only about 14 (Crompton et al. 2010; Crompton 2011), a figure small in relation to the 100 or so lives lost annually in structure fires (Ashe, McAneney and Pitman 2009).

In the case of structural fires, a study of fatalities in residential homes by Brennan (1999) concluded that fire victims are some of the most vulnerable people in our community and yet they are likely to be housed in accommodation that provides them with little support in a fire emergency. The findings also highlighted the necessity for adapting preventative education for each at-risk group. Safety programs directed at the general public, whether they are about increasing awareness of and reducing hazards, improving understanding or modifying behaviour, are unlikely to have an impact on people who have other urgent and more immediate problems related to everyday survival. Engineering and design solutions offer a partial solution but much wider issues of social equity are raised by the fire fatalities.

\section{Conclusions}

This paper has investigated the opportunity cost of regulation in terms of mortality induced by the wealth decline arising from government interventions in fire management. The wealth decline necessary to induce a regulatory fatality, the so-called willingness to pay, in Australia is between A $\$ 20$ million and A \$50 million and, if the overinvestment in fire prevention, management and response 
were around $\mathrm{A} \$ 4500$ million, this would be equivalent to an annual death toll of between 90 and 225 lives. These figures are of the same order as the average annual loss of life due to fires $(\sim 114)$. Whether the overinvestment is of this order or not is immaterial; the important issue is that efforts to reduce risk by regulatory intervention must not cost more in terms of regulatory or statistical fatalities than the lives that might be saved by such intervention.

Our study also explored the consequences of a minimal-interventionist approach to addressing the fire risk in Australia, something that might result in significant economic savings but likely substantially increase the annual death toll from firerelated incidents to somewhere near the current loss of life in traffic accidents. We suspect this increase would be politically unacceptable. It is concluded that the optimum system to address fire safety lies somewhere between the current sub-optimal system and the in extremis minimal-intervention strategy.

No attempt was made to deal with life choices such as those made to live in close proximity to bushlands in fire-prone Victoria, for example (Crompton et al. 2010; Crompton 2011). Rather, our focus has been firmly on the loss of life induced by regulatory interventions that leave people poorer on average. We posit that this cost should be at least roughly in balance with the proposed benefits of improved fire-safety regulations, such as the mandatory use of fire alarms in all residential homes, say, to save lives. The importance of other intangible benefits associated with proposed regulatory intervention can be considered once a clear risk-risk benefit is expected based on the WTS methodology explored in this study.

And, lastly, while some might baulk at the idea of putting a cost on human life, most would find it difficult to justify an annual spend of \$1 billion, say, in order to save one more life on average. In reality, trade-offs governing public expenditures are always present - for example, the decision to spend an extra billion on education will come at the expense of a new operating theatre for a hospital or several armoured vehicles for the army. The approach adopted here to estimate the opportunity costs of government investment follows closely that of Keeney $(1990 ; 1997)$ in the US and is not restricted to investments in fire prevention and management. It should prove more generally useful in tempering government investments in a range of other areas in the economy and ensure that the burden of regulation is kept grosso modo in line with the desired outcomes. 


\section{References}

Ashe, B. S. W., McAneney, K. J. and Pitman, A. J. 2009, 'Total Cost of Fire in Australia', Journal of Risk Research 12(2): 121-36.

2011, 'Is the allocation of resources towards mitigation and response to fire in Australia optimal?', Journal of Risk Research 14(3): 381-95.

Ashe, B. S. W. and McAneney, K. J. 2011, 'Perception of Fire Risk in Australia', Journal of Risk Research (in review).

Brennan, P. 1999, 'Victims and survivors in fatal residential building fires', Fire and Materials 23: 305-10.

Bureau of Infrastructure, Transport and Regional Economics 2011, Road deaths in Australia - October 2011. Department of Infrastructure and Transport, ISSN 1449-1168.

Chen, K. and McAneney, J. 2010, 'Bushfire Penetration into Urban Areas in Australia: A Spatial Analysis', Invited report to the Royal Commission into the 2009 Victorian Bushfires. Risk Frontiers.

Crompton, R. P. 2011, 'Response to Nicholls (2010) on “Influence of Location, Population and Climate on Building Damage and Fatalities due to Australian Bushfire: 1925-2009'", Weather, Climate and Society 3:63-6, doi: 10.1175/ WCAS-D-11-00002.

Crompton, R. P., McAneney, K. J., Chen, K., Pielke Jr., R. A. and Haynes, K. 2010, 'Influence of Location, Population and Climate on Building Damage and Fatalities due to Australian Bushfire: 1925-2009', Weather, Climate and Society 2: 300-10.

Economist 2004, 'Living Dangerously - A survey of risk. The price of prudence', 22 January 2004.

Flynn, J., Slovic, P. and Kunreuther, H. (eds) 2001, Risk, media, and stigma, London: Earthscan.

Frerichs, R. R., Chapman, J. M., Nourjah, P. and Maes, E. F. 1984, Cardiovascular Diseases in Los Angeles 1979-1981, American Heart Association-Greater Los Angeles Affiliate, Inc., Los Angeles, California.

Gerdtham, U. and Johannesson, M. 2002, 'Do Life-Saving Regulations Save Lives?' Journal of Risk and Uncertainty 24(3) 231-49.

Keeney, R. L. 1990, 'Mortality risks induced by economic expenditures', Risk Analysis 10: 147-59. 
1994, 'Mortality risks induced by the Costs of Regulations', Journal of Risk and Uncertainty 8: 95-110.

1997, 'Estimating Fatalities Induced by the Economic Costs of Regulations', Journal of Risk and Uncertainty 14: 5-23.

Kitagawa, E. M. and Hauser, P. M. 1973, Differential Mortality in the United States of America: A study of Socioeconomic Epidemiology, Cambridge, MA: Harvard University Press.

Lutter, R. and Morrall, J. 1994, 'Health-Health Analysis - A new way to evaluate health and safety regulation', Journal of Risk and Uncertainty 8(1): 43-66.

Marryatt, H. W. 1988, Fire: A Century of Automatic Sprinkler Protection in Australia and New Zealand 1886-1986, Melbourne: Australian Fire Protection Association.

Productivity Commission 2011, Report on Government Services 2011.

Ramachandran, G. 1998, The Economics of Fire Protection, London: E\&FN Spon.

Tengs, Tammy O., Miriam, A. J. S. P., Dana, G. S., Joanna, E. S., Milton, C. W. and Graham, J. D. 1995, 'Five Hundred Lifesaving Interventions and Their Cost-Effectiveness', Risk Analysis 15(3): 369-90.

Viscusi, W. Kip. 1993, 'The Value of Risks to Life and Health', Journal of Economic Literature 31(4): 1912-46.

_ 1994a, 'Risk-Risk Analysis', Journal of Risk and Uncertainty 8: 5-17.

— 1994b, 'Mortality Effects of Regulatory Costs and Policy Evaluation Criteria', RAND Journal of Economics 25: 94-109.

Wildavsky, A. 1980, 'Richer is Safer', The Public Interest 60: 27-9. 1988, Searching for Safety, New Brunswick: Transaction Books.

World Health Organisation 2002, Global Burden of Disease Database (Version 5), WHO Geneva. 